\title{
CONSIDERAÇÕES SOBRE A FIGURA PORTANDO O MODELO DE ARQUITETURA NA ARTE MEDIEVAL
}

Artur Simões Rozestraten ${ }^{1}$

\section{Resumo}

Esta pesquisa em andamento, que conta com o apoio da FAPESP, concentra-se sobre o motivo artístico da figura portando o modelo de arquitetura relacionando-o à arquitetura real e à história do projeto de arquitetura na época para construir novas hipóteses sobre a questão da modelagem tridimensional na arquitetura. $\mathrm{O}$ procedimento metodológico identifica, descreve, analisa e interpreta um corpus iconográfico das representações mais significativas do motivo artístico em foco produzidas na Europa e no Oriente Próximo, entre a queda do Império Romano do Ocidente (séc. V) e o Quattrocento italiano.

Palavras-chave: representação da arquitetura, modelagem tridimensional, iconografia da arquitetura.

\section{Summary}

This research in progress, supported by FAPESP, concentrates on the artistic motif of the figure holding the architectural model in relation with the real architecture and the history of architectural project in order to build new hypotheses on the subject of threedimensional modeling in architecture. The methodological procedure identifies, describes, analyzes and interpretates an iconographic corpus of the most significant representations of the artistic motif in focus produced in Europe and Near-East, between the fall of the Occidental Roman Empire (V AD) and the Italian Quattrocento.

Key-words: architectural representation, three-dimensional modeling, architectural iconography.

Esta comunicação trata de alguns aspectos de minha pesquisa de doutorado em andamento junto ao departamento de História da Arquitetura e Estética do Projeto da Faculdade de Arquitetura e Urbanismo da Universidade de São Paulo, sob a orientação do Prof. Dr. Luiz Munari, e que conta com o apoio da FAPESP.

O objetivo geral deste trabalho é estudar e interpretar o motivo artístico da figura portando o modelo de arquitetura na iconografia medieval relacionando-o à arquitetura real e à história do projeto arquitetônico.

Os objetivos específicos deste trabalho estruturaram o procedimento metodológico empregado que envolve:

1. A identificação de um acervo (corpus iconográfico) das representações mais significativas deste motivo artístico entre a queda do Império Romano do Ocidente (séc. V) e o Quattrocento italiano.

2. A descrição plástico-formal e a análise iconográfica de cada uma destas imagens de maneira contextualizada relacionando-as ao seu ambiente histórico-cultural e às formas da arquitetura real onde se inserem.

3. O estudo comparativo das imagens de maneira a facilitar a identificação e a organização de tipologias ou grupos de representações com características plásticas semelhantes.

\footnotetext{
${ }^{1}$ Doutorando junto ao Depto. de História da Arquitetura e Estética do Projeto da Faculdade de Arquitetura e Urbanismo da Universidade de São Paulo.
} 
4. A configuração de hipóteses que auxiliem a compreensão do motivo artístico em questão e suas relações com o papel da modelagem tridimensional no processo de projeto e consequentemente com o trabalho dos arquitetos da época.

Três questões sintetizam as indagações principais desta pesquisa:

I. Qual a história do motivo artístico da figura portando o modelo de arquitetura? Quais os tipos mais característicos, quais suas origens, suas variações e desdobramentos?

II. Que relações haveria entre estas representações de modelos de arquitetura em escala reduzida, a arquitetura real e eventuais maquetes de arquitetos medievais?

III. Que relações podem ser traçadas entre o percurso histórico do motivo em questão e a história do projeto de arquitetura entre o fim do Império Romano do Ocidente e a Renascença?

\section{Antecedentes}

Antes de tratar especificamente das expressões artísticas da figura portando o modelo de arquitetura no mundo medieval cabem aqui algumas considerações sobre os antecedentes históricos deste motivo.

De fato, é possível identificar algumas expressões artísticas da Antigüidade que podem ser interpretadas como antecedentes deste motivo medieval. Estas expressões seriam:

- O costume das culturas neolíticas do sudeste europeu de se valerem de ritos de fundação (bauopfer) envolvendo sacrifícios e oferendas de modelos arquitetônicos.

- O costume egípcio de "apresentar" modelos arquitetônicos como oferendas em rituais de fundação de templos.

- A tradição iconográfica próximo-oriental do cortejo de tributários que registra o uso do modelo de arquitetura como tributo.

- O costume greco-romano de ofertar modelos arquitetônicos em escala reduzida como ex-voto.

- O privilégio de Neokoros e a representação numismática da figura portando o modelo de arquitetura (Lipsmeyer, 1981).

- A iconografia dos estandartes militares romanos ou pompa triumphalis.

- A cultura imperial romana do emprego de maquetes como instrumento de projeto arquitetônico e máquinas de guerra (Vitruvius, 1567; Kalayan, 1971; Will, 1984).

No mosaico da ábside da igreja de S.Vitale em Ravena, à direita do Cristo, o bispo Eclesius apresenta nas mãos, protegidas por seu manto, um modelo arquitetônico da igreja.

Esta imagem é uma das primeiras a caracterizar, no mundo cristão, o motivo artístico da figura portando o modelo de arquitetura. Este motivo, aparentemente, surge na iconografia medieval em meados do séc. VI, como uma criação artística bizantina. A partir desta imagem de Eclesius em S.Vitale este motivo irá permear toda a iconografia da Idade Média, da Armênia à França, com uma série de variações técnicas, estilísticas e alguns desdobramentos temáticos.

$\mathrm{Na}$ época em que os mosaicos foram executados, Ravena, que havia sido a capital do reino visigodo, fora recentemente reconquistada por Belisarius (c.540), principal general do imperador Justiniano. Reintegrada ao Império Romano do Oriente a igreja - martyrium 
de S.Vitale - tornara-se um monumento da reconquista militar, política e religiosa do norte da península itálica.

O tema predominante no programa iconográfico dos mosaicos de S.Vitale é o da oferenda. Figuram ali a cena da oferenda de Abel e Melchisedech, o sacrifício de Isaac por Abrahão, e as oferendas do pão e do vinho da eucaristia trazidos, respectivamente, pelo imperador Justiniano e pela imperatriz Theodora com suas comitivas.

Segundo o cronista Agnellus de Ravena (apud Bungo) no séc. IX havia em S.Vitale uma inscrição, hoje desaparecida, que mencionava o bispo Eclesius como o fundador da igreja - quando a cidade de Ravena ainda estava sob domínio bárbaro - e o banqueiro grego Julianus Argentarius como o financiador da obra. Conforme este registro histórico Argentarius seria o doador propriamente dito da obra de arquitetura; Eclesius o fundador; e S.Vitale, o mártir padroeiro.

Neste contexto, é necessário salientar que quem porta o modelo de arquitetura não é o imperador Justiniano, nem tampouco o general Belisarius, nem mesmo o banqueiro Julianus Argentarius. Quem porta o modelo de arquitetura nesta imagem que dá início à história deste motivo artístico medieval é o pater Eclesius.

Esta caracterização da figura que porta o modelo de arquitetura como pater ecclesia, fundador da igreja, revê perspectivas historiográficas simplificadoras que reúnem sob a designação genérica de "iconografia do doador" expressões artísticas medievais ainda pouco conhecidas, desconsiderando suas peculiaridades estilísticas, variações regionais e amplitude de significados.

Não estariam os mosaicos bizantinos de Ravena compondo uma expressão artística original que re-significa, no universo cristão, os antigos temas pagãos da fundação, da oferenda, da revelação e do tributo?

Aparentemente, em Ravena, Eclesius assume o lugar histórico do "portador do modelo" que outrora fora do tributário de Khorsabad, da deusa Tychè, e da jovem de Cysique. Ao invés de uma suposta ruptura medieval com a arte e a cultura antigas, o motivo da figura portando o modelo de arquitetura no mosaico de S.Vitale, como forma simbólica, reafirma um vínculo de continuidade entre as representações artísticas do mundo bizantino e da Antigüidade clássica.

Para uma melhor caracterização deste fenômeno artístico serão apresentadas a seguir algumas considerações sobre o motivo em questão organizadas a partir das técnicas artísticas utilizadas, a saber: os mosaicos, os relevos e os afrescos.

\section{Os Mosaicos}

Entre o séc. VI e o séc. IX a técnica do mosaico predomina na representação do motivo artístico da figura portando o modelo de arquitetura. Algumas características comuns podem ser identificadas neste conjunto de imagens em mosaico:

- As representações concentram-se em Ravena, Parenzo e Roma.

- Todas as representações estão no interior das igrejas, e a figura em foco localiza-se invariavelmente na abside sobre o altar-mor.

- Nos mosaicos, quem porta o modelo é ou o bispo ou o próprio Papa trajando, na maioria dos casos, manto e estola.

- A figura participa de uma estrutura compositiva centralizada, em geral, com número ímpar de personagens (3, 5, 7 ou 9 figuras, no todo). E em geral localiza-se mais próxima da extremidade do que do centro da composição.

- É comum haver ao lado das figuras, no próprio mosaico, o nome do 
personagem.

- A figura é apresentada sempre em posição frontal, e o modelo deslocado para um dos lados, em geral para a esquerda de quem o porta.

- O modelo é seguro com ambas as mãos, mas estas não o tocam, pois estão sempre cobertas pelo manto.

- O modelo mostra, em geral, a fachada principal e uma das laterais da igreja. A representação da arquitetura é predominantemente realista ao menos até meados do séc. VII. Já nos mosaicos do séc. IX predominam representações esquemáticas de grande simplificação formal.

A partir do séc. VIII os mosaicos representando o motivo artístico em questão praticamente desaparecem. É provável que este fenômeno esteja relacionado às intervenções iconoclastas (726-843) que tentaram banir das igrejas bizantinas as representações figurativas. O retorno dos ícones promoveu, ainda que de modo esparso, manifestações tardias do motivo em mosaico das quais cabe citar três exemplos.

O primeiro é o mosaico existente na luneta do exonártex sul da igreja de S.Sofia, datado entre 976 e 1025, que representa o imperador Justiniano portando o modelo de S.Sofia e o Imperador Constantino portando o modelo das muralhas da cidade de Bizâncio ao lado da virgem e do menino. O segundo é o mosaico na abside da igreja de S.Maria Trastevere em Roma, com datação circa de 1140, que retoma, de modo geral, a estrutura compositiva dos antigos mosaicos do séc. VI com 9 personagens. O terceiro é o mosaico existente no nártex interior do mosteiro de Kariye Camii, atual Istambul na Turquia, datado entre 1310 e 1320, que apresenta do logoteta Theodoro Metochites, de joelhos, oferecendo o modelo da igreja ao Cristo. A representação da figura que porta o modelo de arquitetura de joelhos é nova na técnica de mosaico, muito embora encontre antecedentes na postura de Otto I no relevo de Magdeburg (c. 970) e também na postura de Enrico Scrovegni no afresco de Giotto em Pádua (1303-05).

Entre os primeiros mosaicos dos sécs. VI e VII e estes mosaicos tardios valeria ressaltar aqui algumas diferenças:

- As representações em mosaico do motivo em foco originaram-se na península itálica e deslocaram-se para o Oriente, mais especificamente para Constantinopla, atual Istambul.

- Da abside, no interior das igrejas, as representações orientais se deslocaram para a região próxima à porta, o nártex ou o exonártex.

- Em S.Sofia quem porta o modelo não é um eclesiástico, mas o próprio imperador. Esta cena dos imperadores portando os modelos é posterior em cerca de 400 anos ao reinado de Justiniano e integra-se em uma segunda geração de mosaicos composta para substituir os mosaicos originais da igreja seriamente danificados durante o período iconoclasta. Curiosamente este mosaico é contemporâneo às obras de recuperação da cúpula da igreja conduzida pelo arquiteto armênio Trdat, em torno de 989, logo após um violento terremoto (Donabédian, 1991).

- O modelo é seguro com ambas as mãos, e estas o tocam. Este detalhe revela influências orientais, especialmente dos relevos georgianos e armênios, na composição dos mosaicos tardios.

- O modelo mostra, em geral, apenas a fachada principal da igreja. A representação da arquitetura torna-se mais esquemática e idealizada. 
Se a partir de meados do séc. VII as representações em mosaico do motivo da figura portando o modelo de arquitetura tornam-se cada vez mais raras no ocidente, por outro lado, surgem neste período inúmeras representações em relevo na região das atuais Geórgia e Armênia.

\section{Os Relevos}

Muito embora exista o registro de baixos-relevos em pedra representando o motivo em foco desde meados do séc. VII, na Geórgia, o momento de maior vigor desta expressão artística é o séc. X na Armênia. Na Europa Ocidental os relevos e esculturas são posteriores e serão encontrados especialmente na França e na Alemanha entre fins do séc. X e o séc. XIV.

Os relevos orientais apresentam as seguintes características comuns:

- Concentram-se no território da atual Geórgia e Armênia.

- Todas as representações estão no exterior das igrejas, e a posição do motivo varia: ao lado ou sobre a porta, ou no tímpano.

- Nos relevos, quem porta o modelo é um soberano, rei ou príncipe.

- A figura que porta o modelo tanto pode estar posicionada de frente, de perfil ou a $3 / 4$.

- É comum, na Armênia, a partir do séc. X, o uso do recurso artístico do duplo, ou seja, a representação de duas figuras mais ou menos simétricas portando junto o modelo.

- As mãos que seguram o modelo estão sempre visíveis e evidenciadas, especialmente nas representações encontradas na Geórgia entre os séc. IX e X.

- Os modelos datados entre o séc. VII e X são feitos em baixo-relevo e apresentam, em geral, a fachada principal, ou a fachada principal conjugada a uma vista lateral. De modo geral, ao longo deste período a representação da arquitetura é predominantemente sintética e geometrizada.

- A partir do séc. X os relevos dos modelos arquitetônicos tornam-se mais salientes, em alto-relevo, enfatizando a tridimensionalidade da peça como se pretendessem apresentar uma visão completa da arquitetura em todos seus lados. O exemplo mais claro desta ênfase tridimensional nas representações em relevo é o modelo nas mãos do rei Gag(h)ik Ardzrouni na fachada oeste da igreja da S.Cruz na ilha de Aght'amar na Armênia (915-921). Esta intenção artística levada ao extremo conduzirá os relevos armênios à escultura propriamente dita, como é o caso da composição escultórica em duas peças (o rei e o modelo) apresentando o rei $\mathrm{Gag}(\mathrm{h}) \mathrm{ik}$ portando o modelo da igreja de S.Gregório em Ani (1001-1010).

- O modelo arquitetônico em foco é parte de uma seqüência de representações tridimensionais, que se inicia na própria arquitetura da igreja, e que repete, em diferentes escalas e em reduções progressivas, uma mesma forma. Esta seqüência de reduções tendendo ao infinito remete às imagens geradas pelo reflexo de um mesmo objeto em dois espelhos paralelos dispostos frente à frente. Nestas seqüências de formas, a volumetria geral da igreja é repetida em escala reduzida nos acrotérios, como pequenas igrejas suspensas sobre os telhados; nos sacrários e relicários existentes no interior da igreja, e por fim no modelo arquitetônico. Esta solução artística pode ser observada com clareza 
nas igrejas armênias de Sanahin, Aghthamar, Haridjavank e Zoravar, dentre outras (Cuneo, 1969).

Ao longo dos sécs. XI e XII os relevos orientais apresentando o motivo da figura portando o modelo de arquitetura tornam-se cada vez mais raros. Esta iconografia será retomada na Armênia no início do séc. XIII, mas logo depois desaparecerá.

Neste período de declínio da representação em relevo, entre o ano 1000 e 1300, registra-se, concomitantemente, um fenômeno plástico bastante peculiar.

Trata-se da aparente "perda de peso" do modelo arquitetônico em certas composições nas quais as proporções do modelo são incompatíveis com o gesto de quem o porta. É como se o modelo, apesar de grande, fosse feito de um material surpreendentemente leve. Esta característica formal comparece pela primeira vez, ao que tudo indica, no frontão leste da igreja de Korogo na Geórgia (séc.X); reaparece de forma bastante evidente na escultura do Rei Gag(h)ik em Ani, Armênia (1001-1010); é evidenciada no modelo que levita no relevo de Dadivank, Armênia (1183-1211); e desdobra-se na composição com o modelo elevado sobre a cabeça das figuras nos dois relevos existentes no tambor da igreja de S.Johannes Mkrtich no monastério de Gandzasar, Armênia (1216-1238). Esta "perda de peso" dos modelos que comparece nas representações tardias em relevo será característica das primeiras representações do motivo em foco em afresco, a partir do último terço do séc. XI. Tal característica plástica evidencia uma abstração da representação do modelo, que distanciado da realidade figurativa, ganha liberdade plástica e autonomia formal.

As representações em relevo do motivo em questão, que têm origens orientais, encontrarão expressões significativas na Europa Ocidental somente a partir de fins do século X.

As primeiras expressões deste motivo são identificadas na Alemanha, em Magdeburg (c.970) e Aachen (c.1215), e valem-se de materiais preciosos como o marfim e a prata para aplicar o relevo a pequenas áreas (antependium ou altares) e objetos (relicários).

Outras duas expressões escultóricas são características da representação do motivo estudado na arte medieval da Europa Ocidental: os jacentes e as estátuas.

Os jacentes são esculturas tumulares, e em alguns exemplos, apresentam a figura portando o modelo de arquitetura. Esta representação artística, aparentemente, tem origem com o túmulo do rei Childebert em S.Denis (c.1170) e depois comparece na igreja de S.Blaise em Brunswick na Alemanha (c.1220) no túmulo de Henrique, o Leão. Em meio às representações tumulares há uma expressão em particular que interessa especialmente a este estudo: a inscrição na lápide do arquiteto Hugues Libergier (c.1267) na catedral de Reims na França. Nesta representação, pela primeira vez na cronologia do motivo em foco, o modelo aparece nas mãos de um arquiteto.

A segunda são as estátuas góticas independentes, ou autônomas, como a da porta oeste da catedral de Tuy na Espanha (1215-25) e a de Carlos V (c.1370). A força desta tradição escultórica medieval irá ecoar na arte renascentista no séc. XV com a estátua de S.Petronius de Michelangelo na igreja de São Domenico em Bologna (1494-1495), e a estátua do Arcanjo Michel hoje no Museu de Arte da Catalunha em Barcelona (séc. XV).

As variações formais trazidas pelos relevos armênios à representação do motivo da figura portando o modelo de arquitetura irão influenciar profundamente as expressões em afresco características da arte balcânica na Baixa Idade Média. 


\section{Os Afrescos}

É provável que as representações em afresco do motivo estudado tenham surgido na Itália, ainda no séc.VIII, como uma alternativa mais barata do que o mosaico para a ornamentação do interior de igrejas modestas. Provavelmente a Itália foi o primeiro pólo irradiador desta expressão artística que a partir do séc. XI migrou para a Croácia e finalmente enraizou-se nos Bálcãs.

É precisamente na região da Macedônia (a partir do séc. XII), e um pouco mais tarde na Sérvia e Montenegro (a partir do séc. XIII), que se concentram os mais significativos afrescos do motivo da figura portando o modelo de arquitetura. Considerando a profusão de exemplos, e a qualidade artística destes afrescos balcânicos, é provável que esta região tenha se tornado um segundo pólo irradiador do motivo em questão para o leste europeu, atingindo a Bulgária, a Romênia e mesmo a Ucrânia e a Rússia.

A diversidade de composições em afresco sobre o motivo em pauta dificulta a identificação de características comuns a estas expressões artísticas, no entanto, cabe mencionar algumas características típicas:

- As principais representações concentram-se nos Bálcãs.

- Em virtude da técnica do afresco todas as representações encontram-se no interior das igrejas, mas não necessariamente na abside. Há afrescos localizados na largura do arco cruzeiro e mesmo na nave.

- Geralmente quem porta o modelo é um príncipe, rei ou senhor local. Em algumas representações, no entanto, quem porta o modelo é um eclesiástico ou um patriarca.

- É comum a representação do casal real, lado a lado, sendo que o homem é quem porta o modelo.

- As figuras tanto são representadas em posição frontal quanto a 3/4 e o modelo é sempre deslocado para um dos lados.

- As mãos estão invariavelmente visíveis e tocam o modelo. Há na representação do motivo uma variação na qual a figura segura o modelo com as duas mãos, e outra na qual o modelo é seguro por uma mão enquanto a outra o aponta.

- O modelo mostra, em geral, a fachada principal e uma das laterais da igreja. A representação da arquitetura é predominantemente realista.

Um exemplo interessante do motivo estudado na técnica de afresco encontra-se na capela Scrovegni em Pádua. Neste afresco datado entre 1303 e 1305, Giotto apresenta Enrico Scrovegni, o financiador da capela, ajoelhado recebendo o modelo arquitetônico da capela. Este modelo bastante grande é sustentado nos ombros por um religioso, em primeiro plano, e ao fundo três figuras aureoladas o apresentam ao donatário. Invertendo a cena tradicional da doação Giotto reinventa a iconografia do doador da capela que não é mais quem a oferece, mas quem a recebe.

\section{Variações sobre o motivo}

As mais conhecidas variações sobre o motivo da figura portando o modelo de arquitetura são as iconografias dos santos que têm como emblema o modelo arquitetônico. Este emblema aplica-se com maior freqüência a Santa Bárbara portando a torre e São Jerônimo portando a igreja. Mas há também outras expressões desta variação na iconografia de S.Wolfang, S.Domenico, S.Elizabeth, S.Henri e S.Cunegonda, S.Bonaventura, S.Petronio e mesmo da Virgem Maria.

Nestas representações são raras as relações entre o modelo representado e uma 
arquitetura real. Trata-se, quase sem exceção, de representações estilizadas de uma arquitetura genérica, dentro dos padrões estéticos da época, sem relações diretas com uma arquitetura específica. No caso da torre de S.Bárbara esta estilização é ainda mais evidente. As torres representadas são formas artísticas autônomas, livres de qualquer relação de semelhança com alguma torre específica.

Tudo indica que esta iconografia é posterior ao séc. XII e seus desdobramentos, em diferentes técnicas (pintura, escultura e vitral), atravessam todo o Renascimento e o Barroco. Esta iconografia dos santos também evidencia a inadequação de uma nomenclatura genérica que reduza a complexidade do tema sob a designação: "imagens do doador". Não se tratam de doadores, mas sim de protetores, patronos e padroeiros.

Outra variação é justamente aquela que emprega o modelo de arquitetura como atributo ou emblema do arquiteto. Um dos exemplos mais antigos desta variação na arte medieval é a já citada pedra lapidar do arquiteto Hugues Libergier (c. 1267) que vincula o motivo em foco diretamente ao apogeu do gótico francês.

Se em Ravena Eclesius tomara o lugar histórico do "portador do modelo" que na Antigüidade foi ocupado pelo tributário de Khorsabad e pela deusa Tychè; no final do séc. XIII o arquiteto Libergier, ainda que em sua lápide, assume o papel histórico de quem porta o modelo de arquitetura - ocupando a posição que ao longo de 600 anos fora exclusiva de papas, bispos, reis e príncipes - deixando evidente a valorização do arquiteto na sociedade francesa da Baixa Idade Média como um prenúncio da Renascença.

\section{Referências Bibliográficas}

BUNGO, E. Mosaics of Saint Vitale.

CUNEO, P. Les Modèles en pierre de l'architecture arménienne. Revue des Études Arméniennes, Paris, tome VI, p. 200-231, 1969.

. Architecttura armena. Roma: De Luca Editore, 1988.

DONABÉDIAN, P. Le point sur l'architecte arménien Trdat-Tiridate, à l'occasion du millénaire de son ouvre. Cahiers archéologiques, 39, Paris: Editions Picard, 1991.

KALAYAN, H. Notes on assembly marks, drawings and models concerning the Roman period monuments in Lebanon, Annales Archéologiques Arabes Syriennes AAAS. Revue d'Archéologie et d'Histoire, 21, p.269-273, 1971.

LIPSMEYER, Elizabeth. The donor and his church model in medieval art from early christian times to the late romanesque period. Diss. State University, New Brunswick, N. J. 1981.

VITRUVIO, M. I dieci libri dell'architettura. Veneza: Senefe \& Alemano Campagni, 1567.

WILL, E. La maquette de l'adyton du temple A de Niha (Beqa). In: LE DESSIN D'ARCHITECTURE DANS LES SOCIETES ANTIQUES. Anais do colóquio de Strasbourg, 26-

28 de Janeiro de 1984. Strasbourg: Université des Sciences Humaines de Strasbourg, Centre de Recherche sur le Proche-Orient et la Grèce antiques, 1985. p.277-281. 